\title{
SISTEMA DE INFORMAÇÃO GEOGRÁFICA APLICADO AO LEVANTAMENTO DE SOLOS E APTIDÃO AGRÍCOLA DAS TERRAS COMO SUBSÍDIOS PARA O PLANEJAMENTO AMBIENTAL DO MUNICÍPIO DE ITAARA, RS ${ }^{1}$
}

Everton Luís Poelking ${ }^{2}$, Ricardo Simão Diniz Dalmolin ${ }^{3}$, Fabrício de Araújo Pedron ${ }^{3}$ e Jessé Rodrigo Fink ${ }^{4}$

\begin{abstract}
RESUMO - O planejamento racional de uso dos recursos naturais exige informações a respeito dos solos, as quais são escassas e frequentemente ignoradas pelos gestores ambientais. Assim, objetivou-se realizar o levantamento de solos do Município de Itaara, RS, substituindo a fotointerpretação tradicional pelo uso de cartas topográficas; determinar a aptidão de uso das terras, considerando a legislação ambiental; e estabelecer os conflitos de uso das terras. Utilizando técnicas de geoprocessamento na geração dos planos de informações de solos, declividades, áreas de preservação permanentes, aptidão agrícola e uso atual das terras, foram determinadas as áreas que apresentam conflitos de uso em relação à sua aptidão agrícola e à legislação ambiental. Itaara é constituída, predominantemente, por Neossolos Litólicos (34\%), que apresentam baixo potencial agrícola devido a características do solo e do ambiente onde ocorrem. Por meio do geoprocessamento, identificaram-se pelo menos $6,2 \%$ da área sendo superutilizada.
\end{abstract}

Palavras-chave: Pedologia; Sensoriamento remoto; Conflitos de uso da terra.

\section{GEOGRAPHIC INFORMATION SYSTEM APPLIED TO SOIL SURVEY AND LAND SUITABILITY AS SUBSIDIES FOR ENVIRONMENTAL PLANNING IN ITAARA COUNTY, RS}

\begin{abstract}
The rational planning of use of the natural resources demands information regarding soils, which are scarce and frequently unknown by the environmental managers. In that sense, the aims of this research were to perform the soil survey of the Itaara county, Rio Grande do Sul state, substituting the traditional photointerpretation by the use of topographical maps; to determine the suitability of land use, considering the environmental legislation and to establish the conflicts of land use. Using geoprocessing techniques in the generation information plans of soils, steepness, permanent preservation areas, agricultural suitability and land use, it was possible to determine the areas that show use conflicts in relation to their agricultural suitability and to the environmental legislation. Itaara is constituted, predominantly, by Leptosols (34\%), that has low agricultural potential due to its soil characteristics and the environment where they occur. Through geoprocessing tecniques, it was identified that at least $6.2 \%$ of the area is overused.
\end{abstract}

Keywords: Pedology; Remote sensing; Land use conflicts.

\footnotetext{
${ }^{1}$ Recebido em 09.11.2011 aceito para publicação em 01.12.2014.

${ }^{2}$ Universidade Federal do Recôncavo da Bahia, Centro de Ciências Agrárias, Ambientais e Biológicas, Cruz das Almas, BA - Brasil.E-mail: <everton@ufrb.edu.br>.

${ }^{3}$ Universidade Federal de Santa Maria, Centro de Ciências Rurais, Departamento de Solos, Campus Camobi, Santa Maria, RS - Brasil.E-mail: <dalmolinrsd@gmail.com>e < fapedron@yahoo.com>.

${ }^{4}$ Universidade Federal do Rio Grande do Sul, Departamento de Solos, Porto Alegre, RS - Brasil. E-mail: <fink1j@gmail.com>.
}

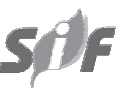

Revista Árvore, Viçosa-MG, v.39, n.2, p.p.215-223, 2015

http://dx.doi.org/10.1590/0100-67622015000200001 


\section{INTRODUÇÃO}

Os levantamentos de solos constituem informações primárias importantes para formação de bancos de dados a cerca da distribuição geográfica dos solos como corpos naturais, em que são previstas e delineadas suas áreas nos mapas e em classes definidas mediante a interpretação de dados analíticos e morfológicos dos perfis modais (EMBRAPA, 1995; DALMOLIN et al., 2004; FLORES et al., 2007). Servem de base para o planejamento de uso das terras e previsão de riscos ou conflitos de uso (EMBRAPA, 1995; KLAMT et al., 2000). O nível de detalhe dessas informações depende da escala e do objetivo para o qual o levantamento será produzido. Para fins de planejamento de uso das terras, em nível de propriedades rurais, microbacias hidrográficas ou municípios, é recomendada a publicação dos mapas em escalas superiores ou iguais a 1:50.000 (DALMOLIN et al., 2004).

Os levantamentos de solos, apesar de serem a base principal para a elaboração de mapas para auxiliar o planejamento de uso das terras, são escassos nas escalas exigidas para o planejamento ambiental em nível de propriedades rurais e gestão municipal. Com o avanço das tecnologias de computação, possibilitou-se a integração da ciência do solo com sistemas computacionais, revolucionando e maximizando os trabalhos em pedologia, como levantamentos de solos e o monitoramento de uso das terras (McBRATNEY et al., 2003), possibilitando a rápida sobreposição e atualização de mapas. A utilização de Sistemas de Informações Geográficas (SIG) em trabalhos de levantamento de solos mostra-se importante ferramenta para análise geoestatística e cruzamento dos diversos planos de informações (PI) gerados a partir dos atributos ambientais (ASSAD et al., 1998; SCULL et al., 2005; PEDRON et al., 2006a), apoio a levantamentos de informações da paisagem (FLORES et al., 2007) e delimitação mais eficiente de Área de Preservação Permanente (APP) (RIBEIRO et al., 2005). Para tanto, mapas de solos são fontes importantes de dados para estudos de gestão de bacias hidrográficas, avaliação ambiental, zoneamento e planejamento de terras, entre outros (WEBBER et al., 2008).

A avaliação da aptidão de uso das terras deve ser o primeiro passo para o seu planejamento racional. A utilização das terras de acordo com a sua aptidão permite maior sustentabilidade ambiental, econômica e social (DENT; YOUNG, 1995). A análise da distribuição espacial e das propriedades dos solos é fundamental para o manejo adequado das terras (FLORINSKY et al., 2002), contribuindo para o planejamento de áreas rurais e urbanas. Várias são as metodologias empregadas para classificação interpretativa das terras, sendo o Sistema de Avaliação da Aptidão Agrícola das Terras (RAMALHO FILHO; BEEK, 1995) o mais utilizado no Brasil, pois prevê a adequação de uso das terras sob diferentes níveis de manejo. No entanto, além da vocação natural dos solos, a legislação brasileira prevê restrição de uso em APP, o que também deve ser levado em consideração no planejamento (RIBEIRO et al., 2005; PEDRON et al., 2006a).

O setor produtivo primário do Município de Itaara, concentrado principalmente na atividade agropecuária, baseia-se em minifúndios de mão de obra familiar. Suas condições fisiográficas como áreas de maior declividade oferecem maior risco à degradação das terras, devido à maior pressão sobre os recursos naturais e à exploração agrícola (PEDRON et al., 2006b).

Diante do exposto, objetivou-se realizar o levantamento de solos do Município de Itaara, RS, utilizando cartas topográficas para separação das diferentes superfícies fisiográficas, bem como determinar a aptidão de uso das terras, levando em consideração a legislação ambiental e estabelecer os conflitos de uso das terras para servir de norteador para as ações de planejamento e uso racional dos recursos naturais, em nível municipal.

\section{MATERIAL E MÉTODOS}

O Município de Itaara está localizado na região central do Rio Grande do Sul, na transição entre a região do Planalto e a Depressão Central, sendo a sede do município localizada a $29^{\circ} 35,5^{\prime}$ de latitude Sul e $53^{\circ} 46^{\prime}$ de longitude Oeste, com área aproximada de $171 \mathrm{~km}^{2}$. O clima da região é do tipo Cfa de Köppen, com regime pluvial anual médio de 1.500 a $1.750 \mathrm{~mm}$, temperatura média mínima anual de $14-15^{\circ} \mathrm{C}$ e média máxima de 23-25 ${ }^{\circ} \mathrm{C}$ (IPAGRO, 1989).

O Modelo Digital de Elevação (MDE) foi obtido a partir da digitalização das curvas de nível das cartas topográficas do Serviço Geográfico do Exército escaneadas, correspondentes às Folhas Camobi-NO e Santa Maria-NE, na escala 1:25.000, com equidistância de $10 \mathrm{~m}$, seguindo as rotinas do aplicativo Spring 5.1.

Revista Árvore, Viçosa-MG, v.39, n.2, p.215-223, 2015

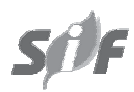


O MDE foi a base para a geração do PI (Plano de Informação) declividade e, posteriormente, do PI Áreas de Preservação Permanente (APP), em que foram extraídas as áreas acima de $100 \%$ de declividade.

Os limites das unidades fisiográficas foram demarcados diretamente sobre as cartas topográficas (em escala 1:50.000), abrangendo a área do município, segundo metodologia preconizada por Flores et al. (2007) e Webber et al. (2008). Essa etapa foi validada por meio da utilização do MDE, que fornece visualização do relevo em terceira dimensão. Dessa maneira, foi simulado o trabalho de fotointerpretação convencional com a substituição dessa etapa no levantamento de solos, obtendo-se, assim, a separação das feições de terreno já referenciadas geograficamente nas cartas topográficas. Os perfis modais foram descritos e coletados segundo a metodologia sugerida por Santos et al. (2005), a partir do mapa preliminar.

As análises físicas e químicas de rotina, como granulometria, $\mathrm{pH}$, carbono orgânico, bases trocáveis $\left(\mathrm{Ca}^{2+}, \mathrm{Mg}^{2+}, \mathrm{K}^{+}, \mathrm{Na}^{+}\right)$e acidez potencial $\left(\mathrm{H}^{+}+\mathrm{Al}^{3+}\right)$, foram realizadas segundo metodologias propostas pela Embrapa (1997). Os pontos de coleta de amostras de solos e descrição de perfis foram marcados com GPS de navegação e visualizados no modelo tridimensional, facilitando a localização, ajuste e dimensionamento das diferentes classes de solos para confecção do mapa final. Os perfis foram classificados no Sistema Brasileiro de Classificação dos Solos (EMBRAPA, 2006), na escala final do PI solos de 1:50.000. A partir do PI Solos e por informações obtidas no campo, gerou-se o PI aptidão agrícola das terras, conforme metodologia sugerida por Ramalho Filho e Beek (1995).

A geração do PI APP teve como base o Código Florestal Brasileiro (CFB) (BRASIL, 1965), regulamentado pela Resolução $n^{\circ} 303$, do Conama (2002). Para delimitação das APP ao longo de margens de rios, nascentes e lagos, utilizou-se o arquivo contendo todas as drenagens obtidas pela digitalização das cartas topográficas supracitadas. Na faixa marginal ao longo das drenagens, riachos e rios, foi gerada uma zona (buffer) de largura correspondente a $30 \mathrm{~m}$, pois todos os rios no município possuem largura de até $10 \mathrm{~m}$. Nas lagoas e, ou, lagos com áreas menores que 20 ha, o buffer utilizado foi de $50 \mathrm{~m}$, ao passo que nas lagoas e, ou, lagos com áreas acima de 20 ha o buffer foi correspondente a $100 \mathrm{~m}$. Em todas as nascentes de rios, foi utilizado um buffer com raio de $50 \mathrm{~m}$. Para geração dos buffers, empregou-se a função "mapa de distâncias" do aplicativo Spring. O mapeamento digital das áreas com declividade superior a $100 \%$ foi efetuado pela função "fatiamento". Nos topos de morros e nas linhas de cumeadas, as APP foram delimitadas, identificandose as cotas correspondentes aos topos e as bases dos morros pela função "extração de topos", a qual separa automaticamente o terço superior da elevação, que passa a ser considerado APP.

O PI de aptidão agrícola das terras considerando a legislação vigente, neste trabalho chamado de PI “adequação de uso das terras", foi gerado pelo cruzamento dos PI aptidão agrícola, com base no sistema de Ramalho Filho e Beek (1995), somado com o PI APP, incluso como classe 6 (Figura 1). O PI uso atual das terras foi gerado a partir da classificação digital da imagem obtida pelo satélite CDD/CBERS de abril de 2009, do Município de Itaara, georreferenciada utilizando pontos de controle obtidos no campo, com o auxílio de um GPS de navegação. Foi escolhido o algoritmo classificador estatístico Maxver (máxima verossimilhança). As classes do PI uso atual das terras foi classificada com os seguintes temas: floresta, campo, agricultura, solos exposto e água. Posteriormente, procedeu-se à verificação a campo da confiabilidade das classes de uso da terra na classificação preliminar do mapa gerado e correção de possíveis erros pelo índice Kappa (equação 1).

$$
K=\frac{n \sum_{i=1}^{c} x_{i i}-\sum_{i=1}^{c} x_{i+} x_{+i}}{n^{2}-\sum_{i=1}^{c} x_{i+} x_{+i}}
$$

em que K é a estimativa do coeficiente Kappa, xii o valor na linha i e coluna $\mathrm{i}, \mathrm{xi}+\mathrm{a}$ soma da linha i e $\mathrm{x}^{+}$ i a soma da coluna i da matriz de confusão, n o número total de amostras e c o número total de classes.

Para gerar o PI conflitos de uso, foi feito o cruzamento do PI adequação do uso da terra com o PI uso atual das terras (Figura 1). No PI conflitos de uso, foram identificadas as áreas onde as terras estavam subutilizadas, utilizadas de acordo com a sua capacidade de uso; e as sobreutilizadas, que excedem a capacidade de suportar a exploração agrícola.

Revista Árvore, Viçosa-MG, v.39, n.2, p.p.215-223, 2015 


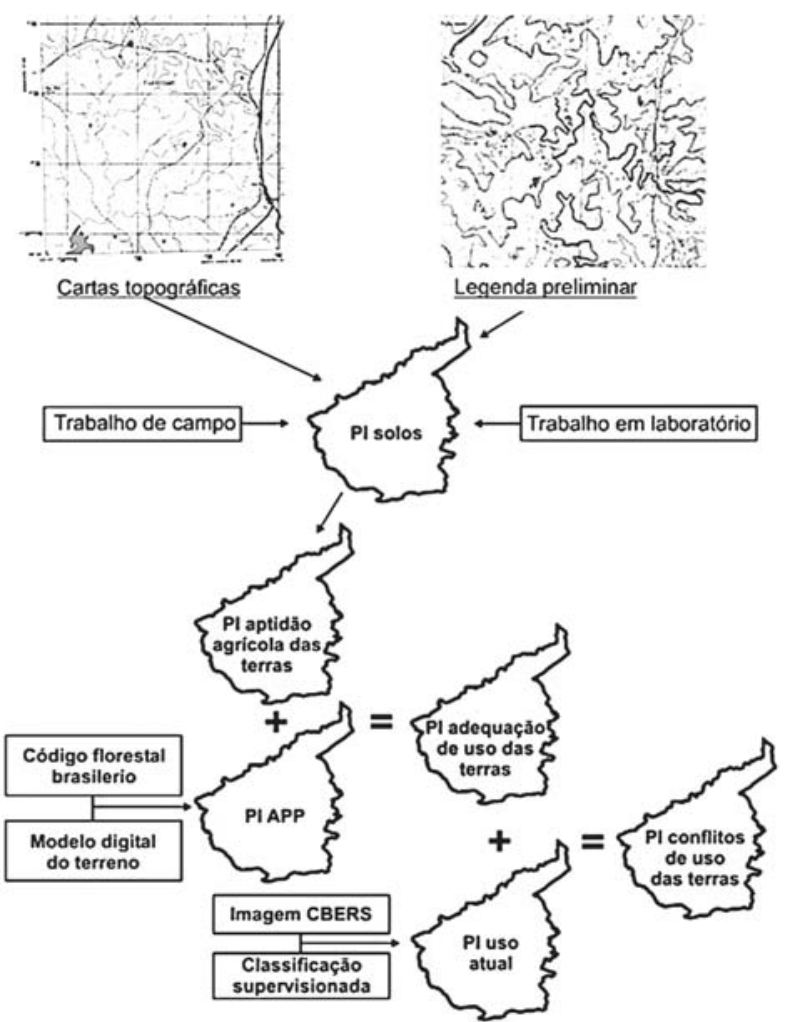

Figura 1 - Esquema de geração do PI Mapa de Adequação de Uso das Terras.

Figure 1 - IP Suitability Land Use Map Generation Scheme.

\section{RESULTADOS}

Os solos encontrados no Município de Itaara são apresentados no PI Solos na escala 1:50.000 (Figura 2a). Foram identificadas as seguintes classes de solos: Argissolo Vermelho, Argissolo Vermelho-Amarelo, Cambissolo Háplico, Chernossolo Ebânico, Neossolo Litólico e Neossolo Flúvico, dispostas em unidades de mapeamento simples e associações de solos. A Tabela 1 apresenta as características de alguns perfis coletados. Os Neossolos e Chernossolos ocorrem, em geral, em condições de relevos mais acidentados sob mata nativa. Por essa razão, apresentam-se com maior fertilidade, com teores de carbono orgânico entre 1,62 e 15,7\%, eutróficos e com menor acidez em comparação com os Argissolos no planalto, no entanto limitam a aptidão agrícola devido à menor profundidade, pedregosidade e declividade. Os Argissolos distribuem-se em condições de relevo suave, são mais profundos e argilosos, porém com menor fertilidade natural e maior acidez ( $\mathrm{pH} 3,7$ a 4,6). São solos com melhor aptidão agrícola devido a poucas limitações físicas, no entanto necessitam de correção da acidez e fertilização para melhorar seu potencial de uso.

Aproximadamente, $34 \%$ do município é composto de Neossolos Litólicos, concentrados nas áreas de maiores declividades com relevo mais acidentado - montanhoso a escarpado -, conferindo com os dados encontrados por Klamt et al. (1997), Pedron et al. (2009) e Dalmolin et al. (2008). Os Neossolos Litólicos em geral apresentam boa fertilidade química, porém são limitados devido à pequena espessura do solo, à pedregosidade e ao relevo acentuado (PEDRON et al., 2006b; STRECK et al., 2008; PEDRON et al., 2009).

Embora não tenham sido mapeadas na escala 1:50.000, existem associações de Neossolos Litólicos com Neossolos Regolíticos e Neossolos Regolíticos com Cambissolos, distribuídas nas áreas onde aparecem os Neossolos Litólicos e os Cambissolos. Os Neossolos Regolíticos caracterizam-se por apresentar contato saprolítico antes do contato lítico, possuindo boas características químicas, que conferem boa fertilidade e teores de carbono orgânico (Tabela 1). Devido ao maior grau de alteração do saprolito em relação à rocha, os Neossolos Regolíticos possuem maior capacidade de sustentação de plantas e retenção de água, em comparação com os Neossolos Litólicos (SCHAFER et al., 1979; OLIVEIRA, 2001). Entretanto, de maneira geral essas áreas com Neossolos apresentam potencial para uso com pastagens quando ocorrem em declividades inferiores a $20 \%$ e para atividades relativas a recreação, turismo rural, reflorestamento e preservação ambiental quando em declividades superiores.

O uso das cartas topográficas para separação das feições fisiográficas facilitou o levantamento de solos, com apoio na atividade de campo, georreferenciamento das informações de campo, espacialização das unidades de mapeamento, conferência e ajuste dos dados. O uso desse procedimento oferece grande vantagem para levantamento de solos de forma mais rápida e com materiais cartográficos já disponíveis em níveis municipal e regional (FLORES et al., 2007; WEBER et al., 2008). Em um país como o Brasil, onde a escassez de mapas de solos prejudica o seu desenvolvimento (DALMOLIN et al., 2004; GIASSON et al., 2006), toda ferramenta que vem auxiliar na reversão desse quadro deve ser considerada.

Revista Árvore, Viçosa-MG, v.39, n.2, p.215-223, 2015 
No Município de Itaara, 2.930 ha, que correspondem a aproximadamente $17 \%$ de sua área total, enquadram-se como APP(Figura 2b). Do total das APP, 77\% são devidos às faixas marginais das drenagens, riachos, rios e lagos do município, enquanto os outros $23 \%$ restantes se devem às áreas dos topos de morro e linha de cumeada e às áreas com declividades superiores a $100 \%$. Conforme a Resolução ${ }^{\circ}$ 303, do Conama (2002), as áreas de APP devem permanecer intactas, sem nenhum tipo de exploração. De acordo com Ribeiro et al. (2005), a
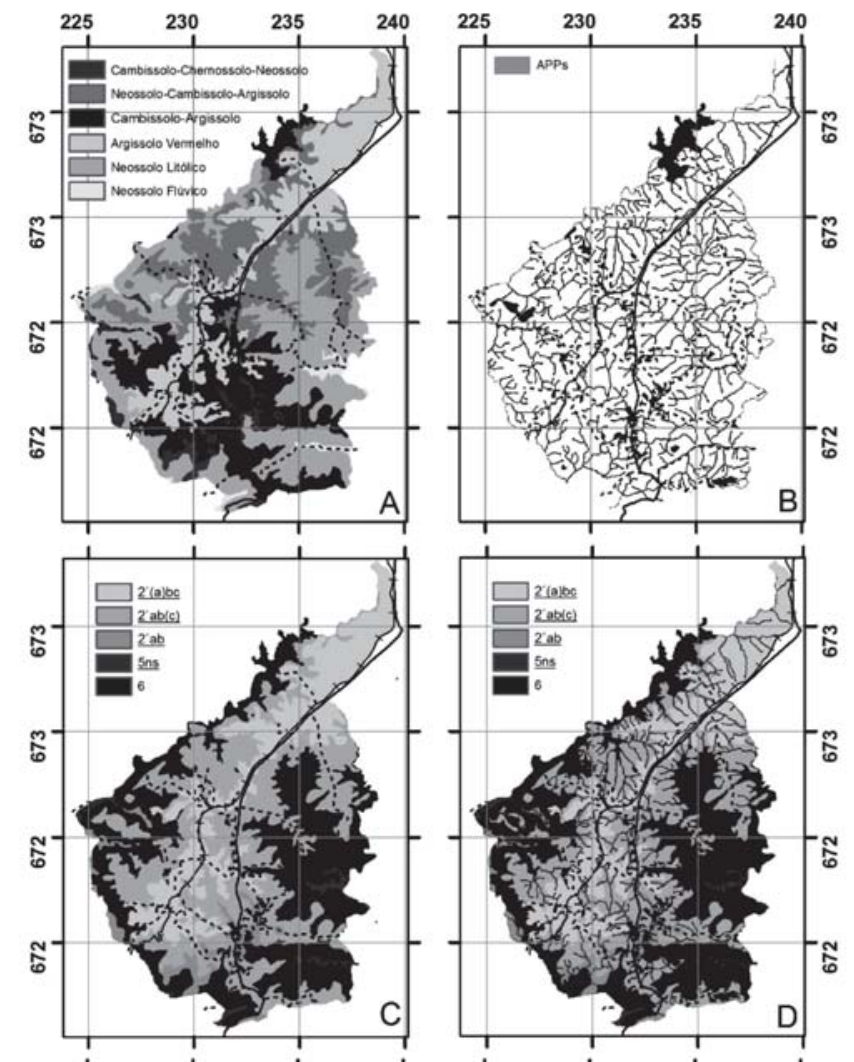

\section{Projeção UTM \\ Datum SAD 69 \\ Zona 22S}

Base cartográfica

Cartas topográficas

Serviço Geográfico

do Exército

Escala: 1: 25.000
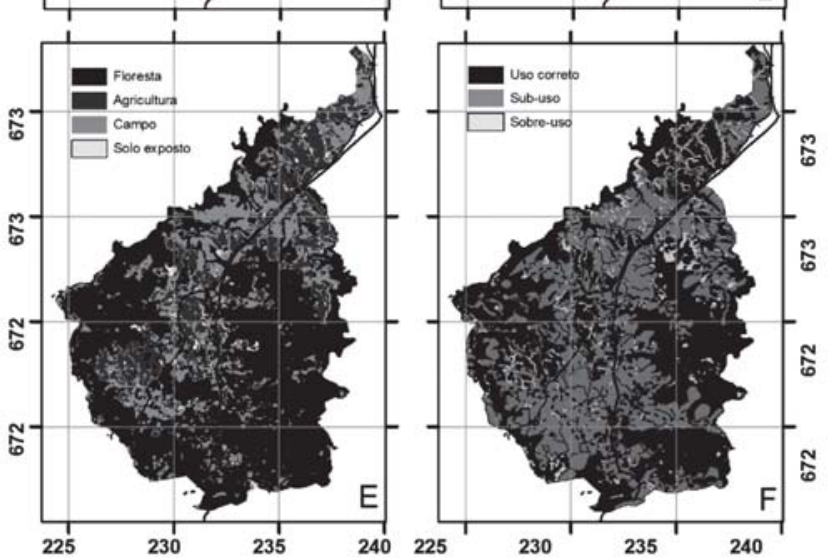

...... Estrada municipal

$\longrightarrow$ Ferrovia

- Rodovia BR 158

Água

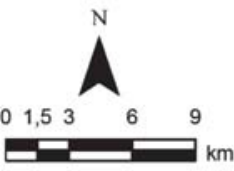

Figura 2 - Mapa de solos (A), Mapa de Áreas de Preservação Permanente (APPs) (B), Mapa de Aptidão Agrícola de Uso das Terras (C), Mapa de Adequação de Uso das Terras (D), Mapa de Uso das Terras (E) e Mapa de Conflitos de Uso (F) do Município de Itaara, RS.

Figure 2 - Soil Map (A), Permanent Preservation Area Map (PPAs) (B), Agricultural Suitability of Land Use Map (C), Suitability for Land Use Map (D), Land Use Map (E) Land Use Conflict Map (F) from Itaara County, RS. 
Tabela 1 - Caracterizações física e química de alguns solos do Município de Itaara, RS.

Table 1 - Physical and chemical characteristics of selected soils of Itaara County, RS.

\begin{tabular}{|c|c|c|c|c|c|c|c|c|c|c|c|c|c|c|}
\hline \multirow{2}{*}{ Horizontee } & \multirow{2}{*}{ Profundidadee } & \multicolumn{3}{|c|}{ Granulometria } & \multirow{2}{*}{ Classe Textural } & \multirow{2}{*}{$\mathrm{pH} \mathrm{H} \mathrm{H}_{2} \mathrm{O}$} & \multirow{2}{*}{ Carbonoo } & \multicolumn{6}{|c|}{ Complexo Sortivo } & \multirow{2}{*}{$\begin{array}{c}\text { Horizonte } \\
\text { V }\end{array}$} \\
\hline & & Areiaa & Siltee & $\overline{\text { Argilaa }}$ & & & & $\overline{\mathrm{Ca}^{2+}}$ & $\mathrm{Mg}^{2+}$ & $\mathrm{K}+\mathrm{H}$ & $\mathrm{H}^{+}+\mathrm{Al}^{3+}$ & $\mathrm{SB}$ & $\overline{\mathrm{CTC}}$ & \\
\hline & $\mathrm{Gm}$ & - & $\mathrm{g} \mathrm{kg}^{-1}$ & - & & $\mathrm{g} \mathrm{kg}^{-1}$ & & 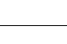 & 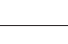 & $-\mathrm{C}$ & molc kg & $g^{-1}$ & - & $\%$ \\
\hline \multicolumn{15}{|c|}{ CHERNOSSOLOARGILÚVICO ÓRTICO } \\
\hline A & $0-26$ & 279 & 525 & 196 & Franco-siltosa & 5,9 & 15,7 & 15,2 & 5,9 & 1,21 & 3,29 & 22,31 & 25,60 & 87,15 \\
\hline $\mathrm{BA}$ & $26-40$ & 354 & 463 & 183 & Franca & 4,7 & 5,8 & 22,8 & 7,8 & 0,78 & 6,04 & 31,38 & 37,42 & 83,85 \\
\hline $\mathrm{B}$ & $40-80$ & 284 & 370 & 346 & Franco-argilosa & 4,4 & 2,9 & 12,5 & 7,3 & 0,53 & 13,68 & 20,33 & 34,01 & 59,78 \\
\hline $\mathrm{BC}$ & $80-100+$ & 562 & 326 & 112 & Franco-arenosa & 4,3 & 2,3 & 5,9 & 6,6 & 0,90 & 18,61 & 13,40 & 32,01 & 41,86 \\
\hline \multicolumn{15}{|c|}{ NEOSSOLO LITÓLICO Eutrófico } \\
\hline A & $0-30$ & 388 & 444 & 168 & Franca & 5,2 & 12,8 & 9,0 & 3,0 & 5,60 & 3,34 & 17,60 & 20,94 & 84,04 \\
\hline A & \multicolumn{13}{|c|}{ NEOSSOLO FLÚVICO Ta Eutrofico } & 74,26 \\
\hline \multicolumn{15}{|c|}{ ARGISSOLO VERMELHO-AMARELO Distrófico Nitossólico } \\
\hline A & $0-28$ & 141 & 476 & 385 & Franco-argilossi & tosa4,2 & 16,2 & 3,2 & 1,4 & 0,18 & 4,95 & 4,78 & 9,73 & 49,11 \\
\hline $\mathrm{AB}$ & $28-42$ & 245 & 389 & 434 & Argila & 4,0 & 13,9 & 1,6 & 0,8 & 0,08 & 5,78 & 2,48 & 8,26 & 30,01 \\
\hline $\mathrm{BA}$ & $42-58$ & 111 & 425 & 436 & Argilossiltosa & 4,0 & 11,6 & 1,6 & 2,6 & 0,07 & 5,89 & 4,27 & 10,16 & 42,04 \\
\hline B1 & $58-88$ & 40 & 183 & 777 & Muito argilosa & 4,1 & 8,7 & 1,4 & 0,7 & 0,07 & 5,73 & 2,17 & 7,90 & 27,46 \\
\hline B2 & $88-140+$ & 46 & 215 & 739 & Muito argilosa & 4,7 & 2,3 & 0,9 & 2,8 & 0,07 & 4,43 & 3,77 & 8,20 & 45,96 \\
\hline \multicolumn{15}{|c|}{ ARGISSOLO VERMELHO-AMARELO Distrófico } \\
\hline A & $0-40$ & 160 & 415 & 425 & Argilossiltosa & 3,9 & 1,62 & 0,8 & 0,6 & 0,08 & 6,82 & 1,48 & 8,3 & 17,82 \\
\hline $\mathrm{AB}$ & $40-65$ & 113 & 307 & 580 & Argila & 3,8 & 1,16 & 0,5 & 0,3 & 0,06 & 6,93 & 0,86 & 7,78 & 11,04 \\
\hline B1 & $65-90$ & 82 & 277 & 641 & Muito argilosa & 3,9 & 0,69 & 0,2 & 0,1 & 0,05 & 5,89 & 0,35 & 6,23 & 5,61 \\
\hline B2 & $90-115$ & 88 & 293 & 619 & Muito argilosa & 4,3 & 0,4 & 0,3 & 0,2 & 0,06 & 4,9 & 0,56 & 5,46 & 10,25 \\
\hline $\mathrm{BC}$ & $115+$ & 91 & 352 & 557 & Argila & - & - & - & - & - & 5,16 & - & 5,16 & - \\
\hline \multicolumn{15}{|c|}{ NEOSSOLO REGOLÍTICO Eutrófico } \\
\hline A & $0-30$ & 231 & 444 & 325 & Franco-argilosa & 4,2 & 1,62 & 2,4 & 1,1 & 0,35 & 5 & 3,85 & 8,85 & 43,48 \\
\hline $\mathrm{CR}$ & $30-78$ & 219 & 437 & 344 & Franco-argilosa & 4,1 & 1,1 & 1,2 & 0,7 & 0,41 & - & 2,31 & 2,31 & 100 \\
\hline \multicolumn{15}{|c|}{ ARGISSOLO VERMELHO Distrófico Nitossólico } \\
\hline A & $0-39$ & 188 & 370 & 442 & Argila & 3,8 & 1,56 & 0,4 & 0,4 & 0,13 & 7,13 & 0,93 & 8,06 & 11,53 \\
\hline $\mathrm{AB}$ & $39-58$ & 139 & 270 & 591 & Argila & 3,7 & 1,21 & 0,4 & 0,2 & 0,1 & 6,93 & 0,7 & 7,62 & 9,18 \\
\hline $\mathrm{BA}$ & $58-85$ & 98 & 275 & 632 & Muito argilosa & 3,9 & 0,75 & 0,5 & 0,5 & 0,93 & 6,2 & 1,93 & 8,13 & 23,74 \\
\hline B & $85-148$ & 96 & 238 & 666 & Muito argilosa & 4,2 & 0,35 & 0,5 & 0,8 & 0,06 & 4,64 & 1,36 & 6 & 22,66 \\
\hline $\mathrm{BC}$ & $148+$ & 108 & 274 & 618 & Muito argilosa & 4,6 & 0,17 & 0,3 & 0,7 & 0,05 & 4,02 & 1,05 & 5,06 & 20,72 \\
\hline
\end{tabular}

SB: Soma de bases, CTC: Capacidade de troca de cátions e V: Saturação por bases.

delimitação automática das APP elimina a subjetividade nos procedimentos de campo e viabiliza o fiel cumprimento do CFB, favorecendo também a fiscalização ambiental. Entretanto, Pedron et al. (2006a) alertaram que a determinação das APP de maneira digital pode levar a uma subestimativa delas, pois há dificuldades em identificar e localizar todas as nascentes, vertentes e olhos d'água distribuídos nas diversas feições fisiográficas de determinada área.

Com relação à aptidão agrícola das terras (RAMALHO FILHO; BEEK, 1995), o Município de Itaara apresenta mais de 6.000 ha (aproximadamente $36 \%$ da área total) sem aptidão (classe 6) ou com aptidão restrita (classe $5 \mathrm{~ns}$ ) para a agricultura (Figura 2c). Essas restrições são devidas às limitações de solos, predominantemente Neossolos Litólicos, e também ao relevo acidentado, conforme pode ser visualizado na Figura 1. Os outros $64 \%$ da área do município possuem aptidão para lavouras, e as restrições na utilização dependem do nível de manejo adotado.

O PI adequação de uso das terras (Figura 2d) é alternativa ao PI sistema de aptidão agrícola das terras gerado com base no sistema proposto por Ramalho Filho e Beek (1995), pois, além de considerarem as características referentes ao solo e à paisagem, levam em conta a legislação vigente que norteia as APP. A

Revista Árvore, Viçosa-MG, v.39, n.2, p.215-223, 2015 
análise do PI adequação de uso das terras indicou o aumento das áreas sem aptidão de uso, passando para $44 \%$ da área total do município. Esse aumento, de aproximadamente 1.800 ha, foi em decorrência da incorporação das áreas de APP como pertencentes à classe sem aptidão para uso agrícola. A área ocupada pela classe de aptidão agrícola $2 " a b(c)-$ classe de terra com aptidão regular para cultivos anuais nos níveis de manejo A e B e aptidão restrita para cultivos anuais no nível de manejo C (Figura 2c) - foi a que apresentou maiores restrições impostas pela legislação, contribuindo com $66 \%$ da área total incorporada como sem aptidão no mapa de adequação de uso.

\section{DISCUSSÃO}

A discussão em relação ao uso da terra, conforme sua aptidão agrícola, deve levar em consideração a legislação ambiental, assim como observado em Pedron et al. (2006ab), porém, frequentemente, ignorada em alguns trabalhos, principalmente quando não efetuados por pedólogos. O mapa de adequação ao uso da terra apresentado neste trabalho pode ser alternativa para o planejamento racional de atividades que exercem pressão sobre os recursos naturais, contribuindo para a mitigação da sua degradação.

O uso atual das terras mostrou que no Município de Itaara a área está sendo utilizada, conforme as classes estabelecidas para este trabalho, de $60,9 \%$ com floresta, $14,2 \%$ com agricultura, $21,6 \%$ com campo e $2,5 \%$ com água e $0,7 \%$ com solo exposto (Figura 2e). A acurácia do mapa verificada pelo índice Kappa atingiu acerto de 0,89 , considerado excelente $(0,8 \leq \mathrm{K}=1)$ (CONGALTON; GREEN, 1998). As florestas, predominantemente nativas, ocupam a maior parte da área e estão localizadas em relevo fortemente ondulado a ondulado, em locais de difícil acesso, em que a exploração agrícola é muito restrita. As áreas ocupadas por agricultura e campo estão, predominantemente, nas áreas de relevo ondulado $\mathrm{e}$ relevo suavemente ondulado, na região denominada Topo do Planalto.

O PI conflitos de uso (Figura 2f) mostra que, aproximadamente, 52,5\% do Município de Itaara apresenta uso correto da área, ou seja, a terra está sendo utilizada dentro de seu potencial máximo de uso sem riscos para a degradação ambiental. Já as áreas que estão abaixo do potencial máximo de uso e que poderiam dar maior retorno econômico ao município somam cerca de 41,3\%. Em geral, são áreas utilizadas com pecuária e que teriam aptidão para a agricultura, com dois cultivos anuais, no inverno e no verão. Devem ser consideradas também aquelas áreas em pousio, ou áreas com integração lavourapecuária, que neste estudo não foram consideradas. As áreas que estão sendo ocupadas acima do seu potencial máximo de uso, segundo o mapa de adequação de uso, atingem $6,2 \%$ da área total do município e estão sujeitas a riscos severos de degradação ambiental. São, principalmente, áreas localizadas em relevos acidentados, ocupados por Neossolos Litólicos e, ou, Cambissolos que não apresentam potencial para lavouras, no entanto são utilizadas para esse fim, no regime de agricultura familiar.

O Município de Itaara, assim como muitos outros localizados na região entre a Depressão Central e o Planalto do Rio Grande do Sul, denominada Rebordo do Planalto, apresenta condições fisiográficas que afetam a formação dos solos e imprimem a essas áreas limitado potencial agrícola. Além disso, a própria condição de relevo dessas áreas contribui para a preservação da floresta nativa, tornando-a corredor ecológico de grande importância na manutenção da fauna e flora regional. Diante do exposto, ressalta-se que as atividades agrícolas devem ser planejadas com informações do recurso solo, visando à manutenção das famílias envolvidas nessa atividade e dos próprios recursos naturais.

A utilização de SIG como ferramenta no estudo de monitoramento do uso e cobertura das terras, aliada à capacidade de sobreposição de diferentes PI no mapeamento e detecção de problemas de utilização das terras, mostrou-se adequada para o Município de Itaara. Oferece grande potencial de utilização em zoneamentos, diagnósticos e ordenação de usos do espaço em planejamentos agrícolas. Com a utilização de SIGs, podem ser realizados planejamentos e uso sustentável das terras, de forma cada vez mais precisa e rápida, integrando dados sobre meio físico com dados socioeconômicos (ASSAD et al., 1998). Além disso, integrar com Sensoriamento Remoto permitiu ao poder público verificar a exequibilidade dos projetos de desenvolvimento local com base na legislação ambiental e na ocorrência do uso inadequado da terra (OLIVEIRA et al., 2008).

\section{CONCLUSÕES}

A área do Município de Itaara é constituída, predominantemente, por Neossolos Litólicos nas encostas declivosas (34\%), apresentando forte restrição

Revista Árvore, Viçosa-MG, v.39, n.2, p.p.215-223, 2015

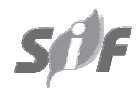


ao uso com agricultura; e Argissolos Vermelhos no Topo do Planalto (22\%), com aptidão regular para uso agrícola.

O mapa de adequação de uso das terras apresenta-se como alternativa ao tradicional mapa de aptidão agrícola das terras, obedecendo à legislação ambiental vigente e contribuindo, de fato, para o planejamento racional do uso das terras e permitindo a identificação de áreas com utilização atual inadequada. O emprego de ferramentas de geoprocessamento permitiu identificar que $52,5 \%$ da área se encontrava em uso inadequado, sendo $41,3 \%$ subutilizada e $6,2 \%$ com utilização acima da sua capacidade.

\section{AGRADECIMENTOS}

Ao CNPq, pela concessão dos recursos financeiros para o desenvolvimento deste trabalho.

\section{REFERÊNCIAS}

ASSAD, M.L.L.; HAMADA, E.; CAVALIERI, A. Sistema de informações geográficas na avaliação de terras para a agricultura. In: ASSAD, E.D.; SANO, E.E. (Ed.) Sistema de Informações Geográficas: aplicações na agricultura. Planaltina: Embrapa-CPAC, 1998. p.191-232.

BRASIL. Lei 4.771, de 15 de Setembro de 1965. Dispõe sobre o Código Florestal Brasileiro. Disponível em: $<$ http:// www.senado.gov.br>. Acesso em: 18 de jul. 2011.

CONGAlton, R. G.; GREEN, K. Assessing the accuracy of remotely sensed data: Principles and practices. New York: Lewis Publishers, 1998. 137p.

CONSELHO NACIONAL DO MEIO AMBIENTE CONAMA. Resolução No 303, de 20 de março de 2002 - Dispõe sobre parâmetros, definições e limites de áreas de preservação permanente. Disponível em: $<$ http://www.mma.gov.br/conama/>. Acesso em: 18 de jul. 2011.

DALMOLIN, R.S.D.; KLAMT, E.; PEDRON, F.A. AZEVEDO, A.C. Relação entre as características e o uso das informações de levantamentos de solos de diferentes escalas. Ciência Rural, v.34, p.1479-1486, 2004.

Revista Árvore, Viçosa-MG, v.39, n.2, p.215-223, 2015
DALMOLIN, R.S.D.; KLAMT, E.; CABRAL, D.R.; PEDRON, F.A. Solos do município de Silveira Martins: Características, classificação distribuição geográfica e aptidão agrícola. Santa Maria: Orium, 2008. 70p.

DENT, D.; YOUNG, A. Soil survey and land evaluation. London: E. FN SPON, 1995. 284p.

EMPRESA RASILEIRA DE PESQUISA AGROPECUÁRIA - EMBRAPA. Centro Nacional de Pesquisa de Solos. Procedimentos normativos de levantamentos de solos. Rio de Janeiro: 1995. 169p.

\section{EMPRESA RASILEIRA DE PESQUISA} AGROPECUÁRIA - EMBRAPA. Centro Nacional de Pesquisa de Solos. Manual de métodos de análise do solo. Rio de Janeiro: 1997. 212p.

EMPRESA RASILEIRA DE PESQUISA AGROPECUÁRIA - EMBRAPA. Centro Nacional de Pesquisa de Solos. Sistema brasileiro de classificação de solos. Brasília: 2006. 306p.

FLORES, C.A. PÖTTER, R.O.; FASOLO, P.J.; HASENACK, H.; WEBER, E.; Levantamento Semidetalhado dos Solos. Região da Campanha - Folha Palomas, RS. Porto Alegre: UFRGS, 2007. 96p.

FLORINSKY, I.V.; EILERS, R.; MANNING, G.; FULLER L. Prediction of soil properties by digital terrain modelling. Environmental Modelling and Software, v.17, p.295-311, 2002.

GIASSON, E.; INDA Jr., A.V.; NASCIMENTO, P.C. Estimativa do benefício econômico potencial de dois levantamentos de solos no Estado do Rio Grande do Sul. Ciência Rural, v.36, n.2, p.478-486, 2006.

INSTITUTO DE PESQUISAS AGROPECUÁRIAS IPAGRO. Seção de ecologia agrícola. Atlas agroclimático do Estado do Rio grande do Sul. Porto Alegre: 1989. 102p.

KLAMT, E.; DALMOLIN, R.S.D.; GONÇALVES, C.N.; INDA Jr, A.V.; ALMEIDA, J.; FLORES, C.A. Proposta de normas e critérios para execução de levantamentos semi-detalhados de solos e para avaliação da aptidão agrícola das terras. Pelotas: NRS-SBCS, 2000. 44p. (Boletim Técnico, 5). 
KLAMT, E.; DALMOLIN, R.S.D.; CABRAL, D.R. Solos do município de São João do Polêsine: classificação, distribuição geográfica e aptidão de uso. Santa Maria: UFSM,

Departamento de Solos, 1997.93p.

MCBRATNEY, A.B.; SANTOS, M.L.M.; MINASNY, B. On digital soil mapping. Geoderma, v.117, p.3-52, 2003.

OLIVEIRA, F.S.; SOARES, V.P.; PEZZOPANE, J.E.M.; GLERIANI, J.M.; LIMA, G.S.; SILVA, E.; RIBEIRO, C.A.A.S.; OLIVEIRA, A.M.S.

Identificação de conflito de uso da terra em áreas de preservação permanente no entorno do parque nacional do Caparaó, Estado de Minas Gerais. Revista Árvore, v.32, p.899-908, 2008.

OLIVEIRA, J.B. Pedologia aplicada. Jaboticabal: FUNEP, 2001. 414p.

PEDRON, F.A.; POELKING, E.L.; DALMOLIN, R.S.D.; AZEVEDO, A.C.; KLAMT, E. A aptidão de uso da terra como base para o planejamento dos recursos naturais no município de São João do Polesine, RS. Ciência Rural, v.36, p.105-112, 2006a.

PEDRON, F.A.; DALMOLIN, R.S.D.; AZEVEDO, A.C.; POELKING, E.L. Utilização do sistema de avaliação do potencial de uso urbano das terras no diagnóstico ambiental do município de Santa Maria, RS. Ciência Rural, v.36, p.468-477, 2006 b.

PEDRON, F.A.; AZEVEDO, A.C.; DALMOLIN, R.S.D.; STÜRMER, S.L.K. MENEZES, F.P. Morfologia e classificação taxonômica de Neossolos e saprolitos derivados de rochas vulcânicas da formação Serra Geral no Rio Grande do Sul. Revista Brasileira de Ciência do Solo, v.33,p.119-128, 2009.
RAMALHO FILHO, A.; BEEK, K. J. Sistema de avaliação da aptidão agrícola das terras. 3.ed. Rio de Janeiro: Embrapa-CNPS, 1995. 65p.

RIBEIRO, C.S.; SOARES, V.P.; OLIVEIRA, A.M.S.; GLERIANI, J.M. O desafio da delimitação de áreas de preservação permanente. Revista Árvore, v.29, p.203-212, 2005.

SANTOS, R.D.; LEMOS, R.C.; SANTOS. H.G.; KER, J.C.; ANJOS, L.H.C. Manual de descrição e coleta de solos a campo. 5.ed. Viçosa, MG: Sociedade Brasileira de Ciência do Solo, 2005. 100p.

SCHAFER, W.M.; NIELSEN, G.A.; NETTLETON, W.D. Morphology of a paralithic contact in a soil over soft sandstone. Soil Science Society of America Journal, v.43, p.383$386,1979$.

SCULL, P.; FRANKLIN, J.; CHADWICK, O.A. The application of classification tree analysis to soil type prediction in a desert landscape.

Ecological Modelling, v.181, p.1-15, 2005.

STRECK, E.V.; KÄMPF, N.; DALMOLIN, R.S.D.; KLAMT, E.; NASCIMENTO, P.C. do; SCHNEIDER, P.; GIASSON, E.; PINTO, L.F.S. Solos do Rio Grande do Sul. Porto Alegre: Emater/RS, 2008. 222p.

WEBER, E.; HASENACK, H.; FLORES, C.A.; PÖTTER, R.O.; FASOLO, P.J. GIS as a Support to Soil Mapping in Southern Brazil. In: HARTEMINK, A.E.; McBRATNEY, A.; MENDONÇA-SANTOS, M.L. (Ed). Digital soil mapping with limited data. Amsterdam: springer, 2008. p.103-112. 